\title{
Effects of experimental Mycoplasma pulmonis infection on sensory neuropeptides and airway mucosa in the rat
}

\author{
T. Norlander*, L. Nilsson**, C. Rivero+, T. Midvedt ${ }^{++}$, \\ M. Lidegran*, B. Carlsöö*, P. Stierna*
}

\begin{abstract}
Effects of experimental Mycoplasma pulmonis infection on sensory neuropeptides and airway mucosa in the rat. T. Norlander, L. Nilsson, C. Rivero, T. Midvedt, M. Lidegran, B. Carlsöö, P. Stierna. COERS Journals Ltd 1997.

ABSTRACT: The effect of airway infection on neurogenic inflammation is not known. The present study examines the effect of Mycoplasma pulmonis infection on the sensory neuropeptides substance $P$ (SP) and calcitonin gene-related peptide (CGRP) in the trigeminal ganglion and in the mucosa of the nose and trachea in rats. We compared germ-free (GF), conventionally raised (CV) and specific pathogenfree $(\mathrm{SPF})$ rats.

The concentrations of SP and CGRP in the nasal mucosa were assessed with immunohistochemistry, and their prohormonal transcripts in the trigeminal ganglion were assessed with Northern blot. Mucosa was also processed for light microscopy and electron microscopy.

SP-like immunoreactivity was greater in the nasal mucosa of infected animals than in uninfected controls. CGRP-like immunoreactivity was greater in the nasal septum, but not in the nasal turbinate, of infected than uninfected animals. In contrast, no change was evident in the expression levels of the prohormonal transcripts in the trigeminal ganglion. Infected nasal and tracheal mucosa was oedematous and locally infiltrated with inflammatory cells. In the nose of uninfected GF rats, subepithelial lymphoid aggregations were scarce and appeared inactive.

We conclude that Mycoplasma pulmonis infection results in increased immunoreactivity of substance $P$, probably within nerves. There was no clear evidence of increased synthesis of the precursors of substance $P$ and calcitonin gene-related peptide.

Eur Respir J 1997; 10: 2334-2342.
\end{abstract}

Depts of $*$ Clinical Sciences, $* *$ Clinical Neuroscience and Family Medicine, and +Orthopedic Surgery, Huddinge University Hospital, and ${ }^{++}$Laboratory of Medical Microbial Ecology, Karolinska Institute, Stockholm, Sweden.

Correspondence: T. Norlander

Dept of Otorhinolaryngology

Karolinska Institute

Huddinge University Hospital

S-141 86 Huddinge

Sweden

Keywords: Calcitonin gene-related peptide, germ-free, immunohistochemistry, Northern blot, substance P, trachea

Received: September 121996

Accepted after revision July 61997

The studies were supported by grants from the Swedish Medical Research Council (project No. 00749), the Swedish Society of Medicine, the Karolinska Institute's Research funds, the Axel $\mathrm{F}$ and Vilna Lindmarker Foundation, the Swedish Otolaryngological Society, the Foundation for Old Servants and the Sigurd and Elsa Golje Memorial Foundation.
Axon reflexes may amplify inflammation in asthma. Noxious stimuli excite sensory nerves in the airway, which then release mediators via local reflexes involving antidromic nerve conduction. These mediators can cause vasodilatation, gland secretion, constriction of bronchi, and, in rodents at least, vascular leakage, i.e. neurogenic inflammation [1]. Neuropeptide mediators can also degranulate mast cells and attract inflammatory cells, so they may potentiate allergic reactions [2]. Proven actions of neuropeptides found in nasal mucosa, such as calcitonin gene-related peptide (CGRP), substance $\mathrm{P}$ (SP) and vasoactive intestinal peptide (VIP), may explain several symptoms of chronic rhinitis, such as nasal blockage and hypersecretion [3]. Noxious stimuli, such as cigarette smoke, cause bronchoconstriction and oedema by local reflexes in certain species $[4,5]$. Pretreatment of these animals with SP antagonists or capsaicin, which depletes nerves of neuropeptides and can even kill sensory neurones, inhibits these responses to cigarette smoke [5].

Sensitization of guinea-pigs to toluene di-isocyanate increases the SP-like and CGRP-like immunoreactivity (SP- and CGRP-LI) in the nasal sensory branches and the messenger ribonucleic acid (mRNA) expression of forerunners to these neuropeptides in the trigeminal ganglia [6]. Similarly, drilling and acid etching of rat teeth induces sprouting of nerves with CGRP-LI [7]. There is some evidence that peptidergic nerves are involved in generating allergic inflammation in humans; application of capsaicin to the nasal mucosa of patients with perennial rhinitis diminishes their symptoms and lessens the CGRP content of their nasal mucosae [8].

Airway infection with Sendai virus or Mycoplasma pulmonis makes airway afferent nerves more sensitive [9], but we do not know whether infections potentiate neurogenic inflammation in airways. Sensory peptides may contribute to the airway defences that overcome infections.

We wished to test whether infection of the upper respiratory tract of rats with $M$. pulmonis increases the content of SP and CGRP neuropeptides in the nasal mucosa. To do this we compared the content of SP- and CGRP-LI in the nasal epithelium from control rats and from those inoculated with this organism. We also compared the content of mRNA encoding for precursors of these two peptides in the trigeminal ganglia of control and infected rats. 


\section{Materials and methods}

In two series of animal experiments, we used Northern blot analysis to study the expression of preprotachykinin (ppT), precursor of SP, and prepro-CGRP (ppCGRP), precursor of CGRP, in the rat trigeminal ganglion after experimental infection. In the second series, we performed immunohistochemical analysis of SP and CGRP in the nasal mucosa and documented histopathological changes in the rat nose and trachea.

\section{Experiment 1}

We used 20 outbred, adult, male, specific-pathogenfree (SPF) Long Evans rats (Møllegaard AIS, Copenhagen, Denmark) and four inbred, adult, germ-free (GF) AGUS rats (raised in our laboratory). SPF rats were selected from a carefully monitored stock declared free of the following specific pathogens after trimonthly culture sampling as prescribed by the Federation of European Laboratory Animal Science Association: Bordetella bronchiseptica, Mycoplasma spp., Pasteurella spp., $\beta$ haemolytic streptococci, Streptococcus pneumoniae, Kilham rat virus, Pneumonia virus of mice, Reo virus type II, Sendai and Corona virus. AGUS rats originated from the Long Evans strain but have since been inbred and kept germ-free for more than 70 generations [10].

We infected 10 of the SPF animals with M. pulmonis (strain 548/82; National Institution of Veterinary Medicine, Uppsala, Sweden) by placing a drop of the broth containing the microorganism on the rat's nostrils. The broth was immediately inhaled by the animal. These animals were decapitated 3 weeks after the infection. The trigeminal ganglia were removed immediately, snapfrozen in liquid nitrogen and stored at $-70^{\circ} \mathrm{C}$ until analysis.

The remaining $10 \mathrm{SPF}$ rats and the four GF AGUS rats were kept in separate isolators and sacrificed without prior infection. Their trigeminal ganglia were processed as described above.

\section{Experiment 2}

Twenty adult AGUS rats were used. Of these, 10 were GF while the remainder had been raised under conventional conditions (CV). The $\mathrm{CV}$ animals came from a stock in which repeated culture samples had revealed no case of Mycoplasma spp. infection during the past $10 \mathrm{yrs}$. We infected five of the GF and five of the CV animals with $M$. pulmonis as described for experiment 1 . The others were used as controls. Each of these four groups was kept in separate isolators. All 20 animals were sacrificed after 3 weeks, whereupon the trigeminal ganglia were dissected.

For immunohistochemical analysis of SP and CGRP, specimens of nasal mucosa were immediately obtained after sacrifice as follows. The nose was removed by a vertical cut in front of the orbits, freed from skin and immersed in $4 \%$ paraformaldehyde in phosphate buffer with $14 \%(\mathrm{v} / \mathrm{v})$ saturated picric acid for $4 \mathrm{~h}$. The nose was then rinsed in cold phosphate buffer with $10 \%$ $(\mathrm{w} / \mathrm{v})$ sucrose and opened by a cut along the midline of the dorsum. Mucosal biopsies $(\sim 3 \times 3 \mathrm{~mm})$ were taken from one side of the septum and the ipsilateral nasal turbinate. Specimens were processed for cryostat sectioning. The remainder of the nose was used for histopathological analysis.

In addition, the tracheae of all rats were removed after sacrifice for morphological and ultra-structural investigation.

The experiments were approved by the local Animal Ethics Committee of the Karolinska Institute and were carried out according to the rules of the Swedish Board of Agriculture.

\section{Northern blot analysis (experiments 1 and 2)}

Expression of ppT and ppCGRP in the trigeminal ganglia was analysed with Northern blot as follows. Total ribonucleic acid (RNA) (10-15 mg) was extracted from the dissected ganglia according to CHOMCZYNSKI et al. [11], heat-denatured and separated on a $1.2 \%$ agarose gel containing $0.7 \%$ formaldehyde in a $1 \times 3-\mathrm{N}-$ morpholinopropanesulphonic acid (MOPS) buffer. The RNA preparations were routinely checked for degradation on an agarose gel and by quantification of ultraviolet (UV) absorption at 260/280 nm. The RNA was blotted onto a Hybond $\mathrm{N}^{+}$filter with $25 \mathrm{mM}$ phosphatebuffered saline (PBS), pH 6.4, which was subsequently baked in a vacuum oven $\left(80^{\circ} \mathrm{C}, 2 \mathrm{~h}\right)$. It was prehybridized overnight at $65^{\circ} \mathrm{C}$ with $5 \times$ saline sodium phosphate ethylene diamine tetra-acetic acid (EDTA) $(1 \times$ SSPE is $0.15 \mathrm{M} \mathrm{NaCl}, 0.01 \mathrm{M} \mathrm{NaH}_{2} \mathrm{PO}_{4}, 0.001 \mathrm{M}$ EDTA, $\mathrm{pH}$ 7.4), $5 \times$ Denhardt's solution, $0.5 \%$ sodium dodecyl sulphate (SDS) and $20 \mu \mathrm{g} \cdot \mathrm{mL}^{-1}$ heat-denatured salmon sperm deoxyribonucleic acid (DNA). The preparation was hybridized overnight at $55^{\circ} \mathrm{C}$ with $4 \times$ saline sodium citrate (SSC; $1 \times \mathrm{SSC}$ is $0.15 \mathrm{M} \mathrm{NaCl}, 0.015 \mathrm{M}$ sodium citrate, $\mathrm{pH} 7.0$ ), $0.02 \mathrm{M}$ PBS, $50 \%$ formamide, $10 \%$ dextran sulphate, $1 \times$ Denhardt's solution, $1 \%$ sarcosyl.

The filters were hybridized with 3 '-end-labelled ( ${ }^{32} \mathrm{P}$ deoxycytidine triphosphate) oligodeoxynucleotide probes complementary to the nucleotide sequences (ns) 325-373 (96\% and 98\% sequence homology against $\alpha$ ppCGRP mRNA and $\beta$-ppCGRP mRNA, respectively; [12]), 124-171 (ppT; [13]) and 393-440 ( $\beta$-actin; [14]). Following hybridization, nylon membranes were washed for $4 \times 15 \mathrm{~min}$ at $65^{\circ} \mathrm{C}$ with $1 \times \mathrm{SSC}, 0.1 \% \mathrm{SDS}$, and exposed to multipurpose autoradiographic films (Amersham International plc, Little Chalfont, UK) for different periods ( $6 \mathrm{~h}$ to 3 days) to ensure that the optical densities were quantified within the linear range of the film response. Filters were subsequently washed at $85^{\circ} \mathrm{C}$ with $1 \times$ SSC and $0.1 \%$ SDS for $2 \mathrm{~h}$ and reprobed. Optical densities were estimated with an image analysis system (IBAS-ZEISS; Kontron Elektronik, Eching, Germany). The relative gene expression of ppCGRP and ppT was estimated in comparison with $\beta$-actin as an internal control. Northern blot analysis was performed on all animals in both series of experiments. Total RNA from infected and control animals was processed and evaluated in parallel throughout the experimental procedures. The optical density values were related to uninfected SPF animals in experiment 1 and to uninfected $\mathrm{CV}$ animals in experiment 2 . The values of these groups served as controls and were set to $100 \%$. 


\section{Immunohistochemistry (experiment 2)}

We analysed the immunoreactivity of the neuropeptides SP and CGRP in nasal mucosa as follows. Mucosal specimens were stored overnight in PBS with $10 \%$ $(\mathrm{w} / \mathrm{v})$ sucrose. Twenty micron transverse sections were cut in a cryostat, mounted on glass slides, briefly airdried and incubated in a solution of $1 \%$ bovine serum albumin (BSA) and $0.3 \%$ (v/v) Triton X-100, for $1 \mathrm{~h}$. The sections were then rinsed in PBS and incubated for $24 \mathrm{~h}$ at $+4^{\circ} \mathrm{C}$ with polyclonal rabbit antisera against CGRP (dilution 1:2,000; Peninsula Belmont, CA, USA), or SP (dilution 1:4,000; generously donated by L. Abdullah and P. Petrusz, Chapel Hill, NC, USA). After additional rinsing, sections were incubated for $60 \mathrm{~min}$ at $20^{\circ} \mathrm{C}$ with tetramethyl rhodamine isothiocyanate (TRITC)-conjugated swine anti-rabbit-immunoglobulin $\mathrm{G}(\mathrm{IgG})(1: 20$; Dakopatts, Denmark). They were then examined blind by one of the investigators (CR), using a Nikon Microphot FX fluorescence microscope with appropriate filter combinations. The intensity of the SP-LI and CGRP-LI and the number of immunopositive nerve fibres were assessed by semiquantification. Each sample was graded according to an arbitrary scale where $0=$ no immunoreactivity, $1=$ slight, $2=$ moderate, $3=$ heavy and $4=$ very intensive immunoreactivity. Kodak Echtachrome $64 \mathrm{~T}$ film was used for photography.

\section{Histology and electron microscopy (experiment 2)}

After sampling of mucosa for immunohistochemical analysis, we re-immersed the noses in 3\% formaldehyde for additional fixation for 3 days. The noses were then decalcified in EDTA, embedded in paraffin wax and serially sectioned along the anterioposterior axis at 500 $\mu \mathrm{m}$ intervals. Sections were mounted on glass slides and stained with Alcian blue-periodic acid Schiff (ABPAS). The trachea was fixed in $3 \%$ glutaraldehyde, rinsed in PBS, postfixed in $1 \% \mathrm{OsO}_{4}$, gradually dehydrated in ethanol and embedded in Epon 812 (Ladd, Burlington, VT, USA). One micrometre sections were cut and stained with toluidine blue for light microscopy. From suitable areas, $70 \mathrm{~nm}$ sections were cut with a diamond knife, mounted on mesh copper grids, covered with polyvinyl film (Formvar; BDH Chemicals Ltd, Poole, UK) and contrasted with uranyl acetate and lead citrate. Preparations were examined in a transmission electron microscope (Philips, Eindhoven, The Netherlands).

\section{Microbiology}

In both experiments, nasal cultures were taken from all infected animals immediately after sacrifice and sent to the National Institution of Veterinary Medicine, Uppsala, Sweden, for isolation of M. pulmonis.

\section{Statistical analysis}

We first analysed differences between experimental groups with the Kruskal-Wallis test. We then examined the Northern blot and immunohistochemical data with the Mann-Whitney U-test. Correlation between the expression of ppCGRP and ppT was determined using the Spearman nonparametric correlation. A p-value of less than 0.05 was considered significant.

\section{Results}

\section{Northern blot analysis (trigeminal ganglia)}

We estimated the expression of the prohormonal transcripts for CGRP and SP in comparison with $\beta$-actin in the trigeminal ganglia using Northern blot analysis with the following findings. All three oligoprobes hybridized to single bands with sizes of 1,000 base pairs (bp) (ppCGRP), 1,100 bp (ppT) and 2,400 bp ( $\beta$-actin), respectively (fig. 1). This is in agreement with findings by other authors [12-14]. In experiment 1, we found a significantly elevated ppCGRP expression in infected SPF rats compared to GF rats (mean \pm SEM $119 \pm 9 \% \quad(n=10)$ versus $65 \pm 13 \%(\mathrm{n}=4), \mathrm{p}<0.05$, Mann-Whitney U-test). There was no difference in the expression of ppCGRP of uninfected SPF rats compared to GF rats $(p=0.075$, Mann-Whitney U-test). The expression of ppT did not differ significantly between these groups (figs. 1 and $2 \mathrm{a})$. The levels of ppCGRP $(119 \pm 9 \%(\mathrm{n}=10)$ versus $100 \pm 7 \%(\mathrm{n}=9))$ and ppT $(117 \pm 8 \%(\mathrm{n}=10)$ versus $100 \pm$

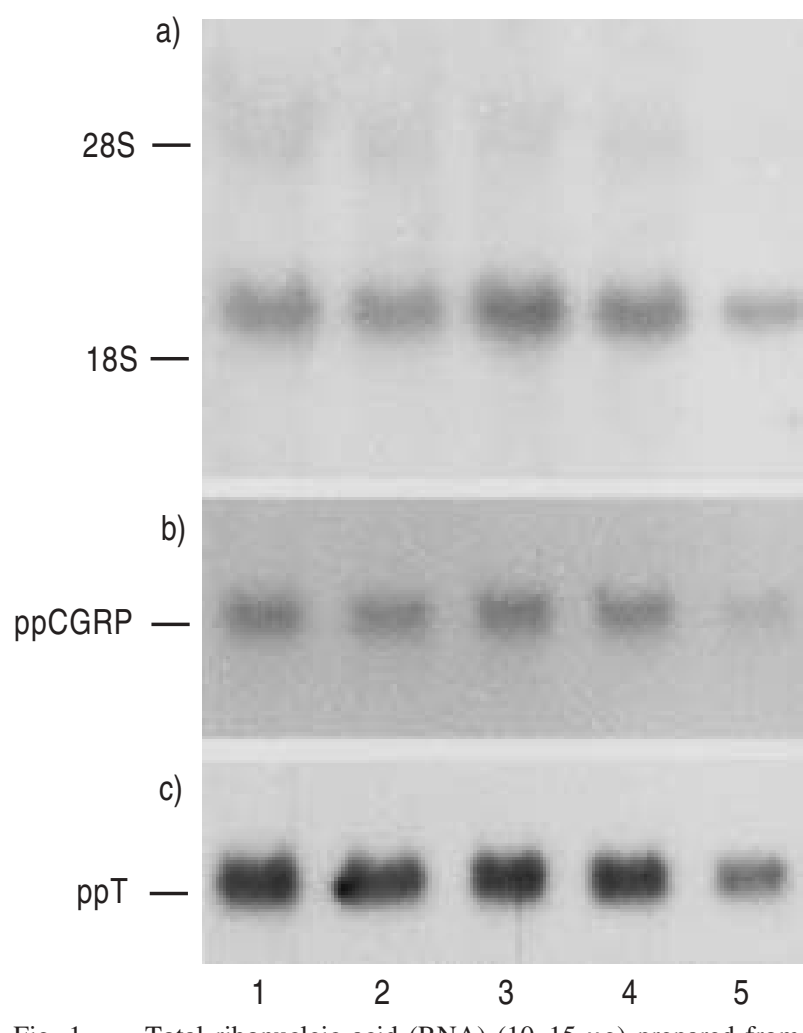

Fig. 1. - Total ribonucleic acid (RNA) (10-15 $\mu \mathrm{g})$ prepared from the trigeminal ganglion of uninfected specific-pathogen-free (SPF) rats $(1,2)$, infected rats $(3,4)$ and germ-free $(\mathrm{GF})$ uninfected rats $(5)$ were hybridized with ${ }^{32} \mathrm{P}-$ labelled oligodeoxynucleotide probes against: a) $\beta$-actin; b) prepro-calcitonin gene-related peptide (ppCGRP); and c) preprotachykinin (ppT)-messenger RNA (mRNA). The RNA samples were separated on denaturing $1.2 \%$ formaldehyde-agarose gel and blotted onto a Hybond- $\mathrm{N}^{+}$filter. The positions of $28 \mathrm{~S}$ and $18 \mathrm{~S}$ ribosomal RNA are indicated (a). 

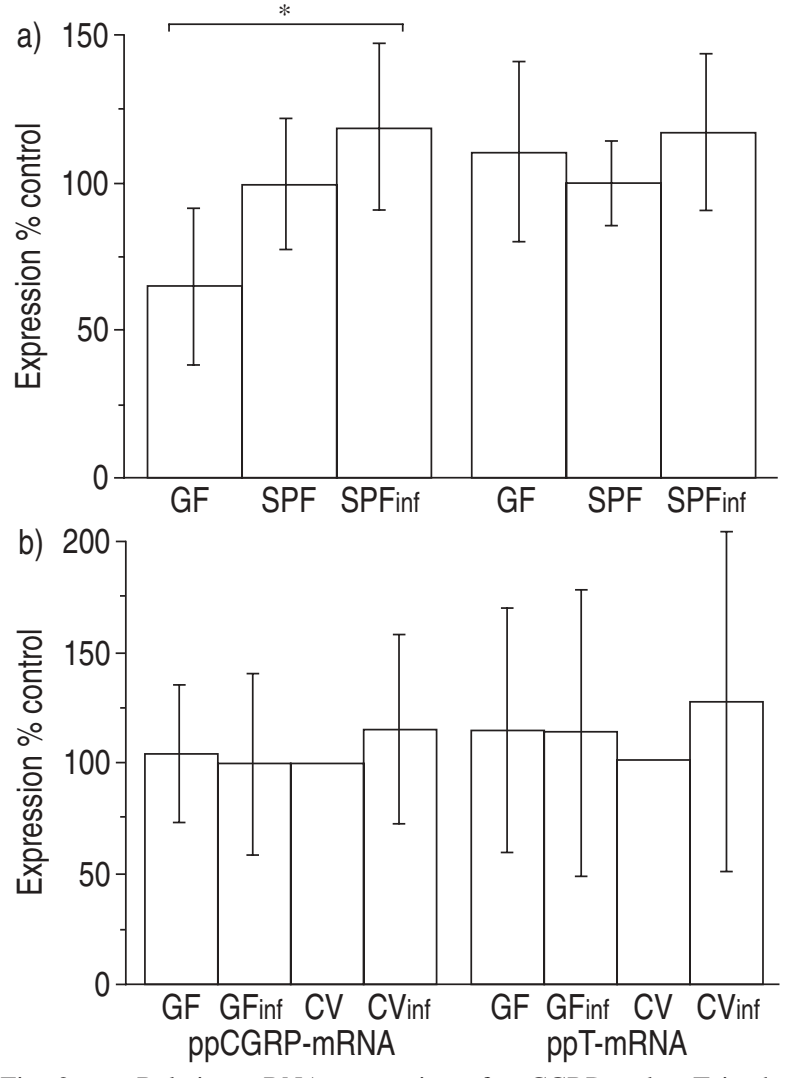

Fig. 2. - Relative mRNA expression of ppCGRP and ppT in the different experimental groups of: a) experiment 1 ; and b) experiment 2 . The expression levels were estimated in comparison with $\beta$-actin mRNA expression as an internal control. Values shown are mean \pm SD. *: p<0.05, Mann-Whitney U-test. GFinf: GF, infected; SPFinf: specificpathogen-free, infected; CV: conventionally raised; CVinf: CV, infected. For further abbreviations see legend to figure 1. For definitions of experiments 1 and 2 , see text.

$5 \%(n=9))$ were higher in infected SPF than in uninfected SPF animals. However, these differences were not significant (ppCGRP: $\mathrm{p}=0.065$; $\mathrm{ppT}$ : $\mathrm{p}=0.18$, MannWhitney U-test). Data for one of the uninfected SPF animals were lost.

In experiment 2, we found no significant difference in the expression of ppCGRP or ppT between infected and uninfected GF rats (ppCGRP: $104 \pm 14 \%(\mathrm{n}=5)$ versus $100 \pm 18 \%(\mathrm{n}=5)$; ppT: $113 \pm 29 \%(\mathrm{n}=5)$ versus $110 \pm$ $25 \%(\mathrm{n}=5))$. The expression of ppT and ppCGRP were slightly higher in infected CV animals than in uninfected CV animals, although the difference was not significant (ppCGRP: $115 \pm 19 \%(\mathrm{n}=5)$ versus $100 \%(\mathrm{n}=5)$; ppT: $127 \pm 34 \%(\mathrm{n}=5)$ versus $100 \%(\mathrm{n}=5)$; fig. $2 \mathrm{~b})$. There was a good correlation between ppCGRP and ppT expression levels (Spearman correlation coefficient $(\mathrm{r})=$ $0.74, \mathrm{n}=23, \mathrm{p}<0.0001$ and $\mathrm{r}=0.86, \mathrm{n}=20, \mathrm{p}<0.0001$ in experiments 1 and 2, respectively).

\section{Immunohistochemical findings (experiment 2)}

We found CGRP-LI and SP-LI in the epithelium, around vessels and glands in mucosa from the nasal septa and nasal turbinates of all animals (fig. 3). When we compared all infected animals to all uninfected animals, semiquantification scores for SP-LI were significantly higher in the septum and nasal turbinate $(\mathrm{p}=0.001)$,
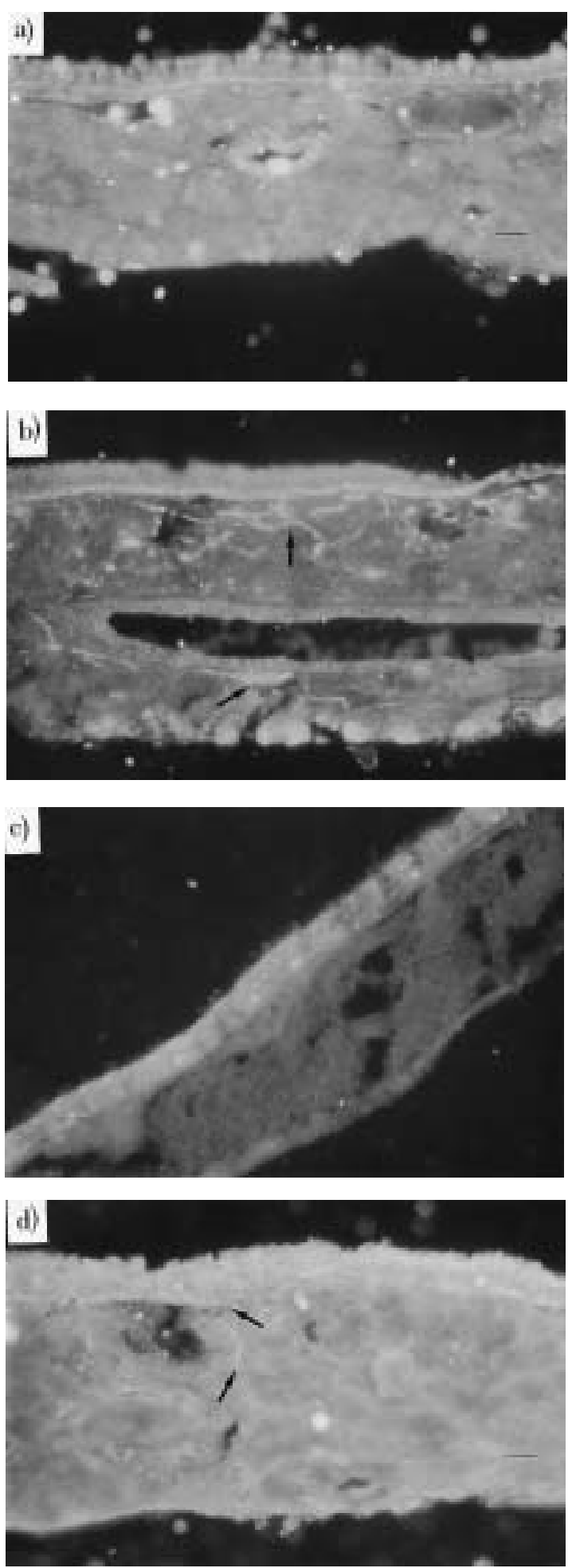

Fig. 3. - Mucosae of nasal septa from rats raised under germ-free (GF) conditions, showing expression: a) of substance P-like immunoreactivity (SP-LI) in a rat without Mycoplasma pulmonis infection; b) of SP-LI in a rat with $M$. pulmonis infection; c) of calcitonin generelated peptide-like immunoreactivity (CGRP-LI) in a rat without infection; and d) of CGRP-LI in a rat with infection. In a) only a few immunopositive fibres can be seen. In b) frequent immunopositive fibres are visible in the basal layers of the epithelium, around glands and vessels (arrows). In c) there is no visible immunoreactivity. In d) a few immunopositive fibres are visible in the basal layers of the epithlium, around glands and vessels (arrows). Internal scale bars $=40$ $\mu \mathrm{M}$. 
Table 1. - Semiquantitive grading of substance P-like immunoreactivity in nasal mucosa (experiment 2)

\begin{tabular}{lccc}
\hline Group & $\begin{array}{c}\text { Rat } \\
\text { No. }\end{array}$ & $\begin{array}{c}\text { Nasal } \\
\text { turbinate* }\end{array}$ & Septum* \\
\hline CV & 1 & 2 & 1 \\
CV & 2 & 2 & 2 \\
CV & 3 & 2 & 1 \\
CV & 4 & 2 & 1 \\
CV & 5 & 2 & 2 \\
Mean & & 2.0 & 1.4 \\
GF & 1 & 2 & 1 \\
GF & 2 & 1 & 1 \\
GF & 3 & 1 & 1 \\
GF & 4 & 2 & 1 \\
GF & 5 & 1 & 1 \\
Mean & & 1.4 & 1.0 \\
CVinf & 1 & 4 & 4 \\
CVinf & 2 & 4 & 3 \\
CVinf & 3 & 3 & 2 \\
CVinf & 4 & 4 & 4 \\
CVinf & 5 & 2 & 2 \\
Mean & & 3.4 & 3.0 \\
GFinf & 1 & 3 & 1 \\
GFinf & 2 & 2 & 3 \\
GFinf & 3 & 4 & 3 \\
GFinf & 4 & 2 & 2 \\
GFinf & 5 & 3 & 4 \\
Mean & & 2.8 & 2.6 \\
\hline
\end{tabular}

*: semiquantitative scores (0: no immunoreactivity; 1 : slight; 2: moderate; 3: heavy; and 4: very intensive immunoreactivity). CV: conventionally raised, uninfected rats; CVinf: conventionally raised rats 3 weeks after experimental infection with Mycoplasma pulmonis; GF: germ-free rats; GFinf: germ-free rats 3 weeks after experimental infection with $M$. pulmonis.

(table 1, fig. 4). CGRP-LI was significantly greater in the nasal septa $(\mathrm{p}<0.05)$ of all infected rats than in those of all uninfected, while CGRP-LI in the nasal turbinate was without significant difference between these groups (table 2, fig. 5).

\section{Histological findings (experiment 2)}

Nose. We found local signs of inflammation, such as oedema, infiltration of leucocytes, and locally purulent

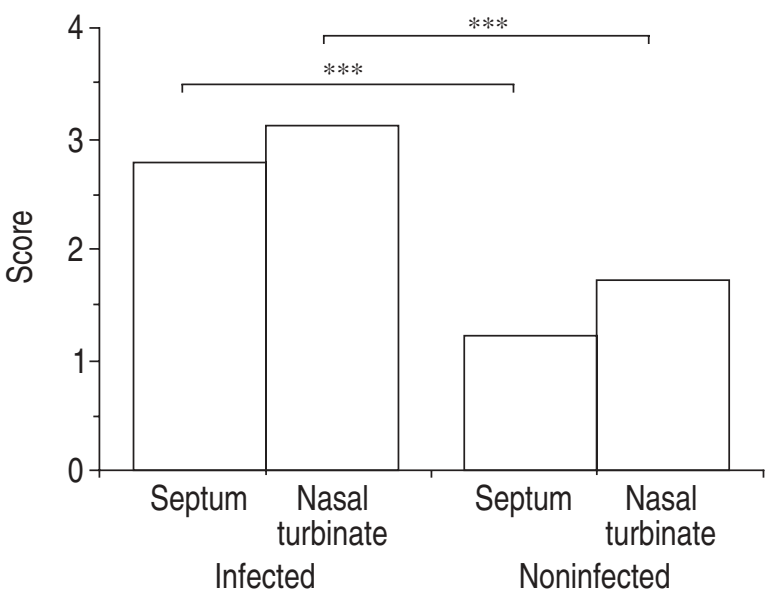

Fig. 4. - Semiquantitative grading of SP-LI in the septum and nasal turbinate of all infected (GF and $\mathrm{CV}$ ) rats compared to all uninfected animals. The differences between the groups were significant for both locations. ***: $\mathrm{p}=0.001$, Mann-Whitney U-test. For definitions, see legend to figures 2 and 3 .
Table 2. - Semiquantitive grading of calciton generelated peptide (CGRP)-like immunoreactivity in nasal mucosa (experiment 2)

\begin{tabular}{|c|c|c|c|}
\hline Group & $\begin{array}{l}\text { Rat } \\
\text { No. }\end{array}$ & $\begin{array}{c}\text { Nasal } \\
\text { turbinate }\end{array}$ & Septum \\
\hline $\mathrm{CV}$ & 1 & 2 & 1 \\
\hline $\mathrm{CV}$ & 2 & 2 & 1 \\
\hline $\mathrm{CV}$ & 3 & 2 & 1 \\
\hline $\mathrm{CV}$ & 4 & 2 & 2 \\
\hline $\mathrm{CV}$ & 5 & 1 & 1 \\
\hline Mean & & 1.8 & 1.2 \\
\hline $\mathrm{GF}$ & 1 & 2 & 0 \\
\hline GF & 2 & 0 & 0 \\
\hline GF & 3 & 0 & 0 \\
\hline GF & 4 & 0 & 0 \\
\hline $\mathrm{GF}$ & 5 & 2 & 2 \\
\hline Mean & & 0.8 & 0.4 \\
\hline CVinf & 1 & 3 & 4 \\
\hline $\mathrm{CV}_{\text {inf }}$ & 2 & 3 & 2 \\
\hline $\mathrm{CV}$ inf & 3 & 2 & 1 \\
\hline $\mathrm{CV}$ inf & 4 & 3 & 0 \\
\hline $\mathrm{CV}$ inf & 5 & 0 & 1 \\
\hline Mean & & 2.2 & 1.6 \\
\hline GFinf & 1 & 0 & 2 \\
\hline GFinf & 2 & 0 & 2 \\
\hline GFinf & 3 & 2 & 2 \\
\hline GFinf & 4 & 1 & 1 \\
\hline GFinf & 5 & 3 & 2 \\
\hline Mean & & 1.2 & 1.8 \\
\hline
\end{tabular}

For definitions of abbreviations and scores, see table 1 .

secretion, in the nasal mucosa of all infected rats with no obvious difference between GF and CV groups (fig. 6). Mucosa of uninfected rats, both GF and CV, appeared normal. However, we noted differences between uninfected GF rats and the other three groups. Subepithelial follicle-like aggregations of lymphocytes (germinal centres) were frequent in the latter groups, while such aggregations were scarce in GF rats (fig. 7). Moreover, diapedesis of leucocytes through the epithelium was very rare in the uninfected GF animals, but frequent in the other groups.

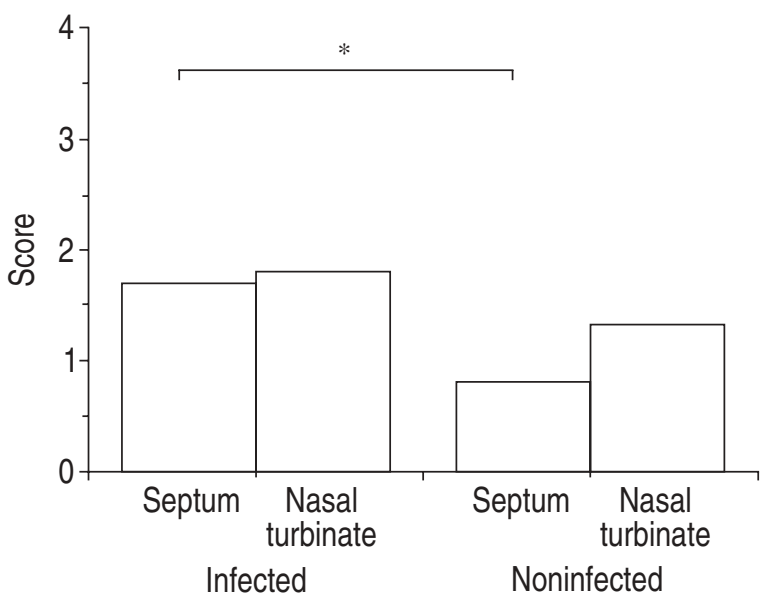

Fig. 5. - Semiquantitative grading of CGRP-LI in the septum and nasal turbinate of all infected (GF and $\mathrm{CV}$ ) rats compared to all uninfected animals. The differences between the two groups were significant for scores of the septum, while those of the nasal turbinate were not. *: $\mathrm{p}<0.05$, Mann-Whitney U-test, after correction for tied values. For definitions, see legend to figures 2 and 3. 


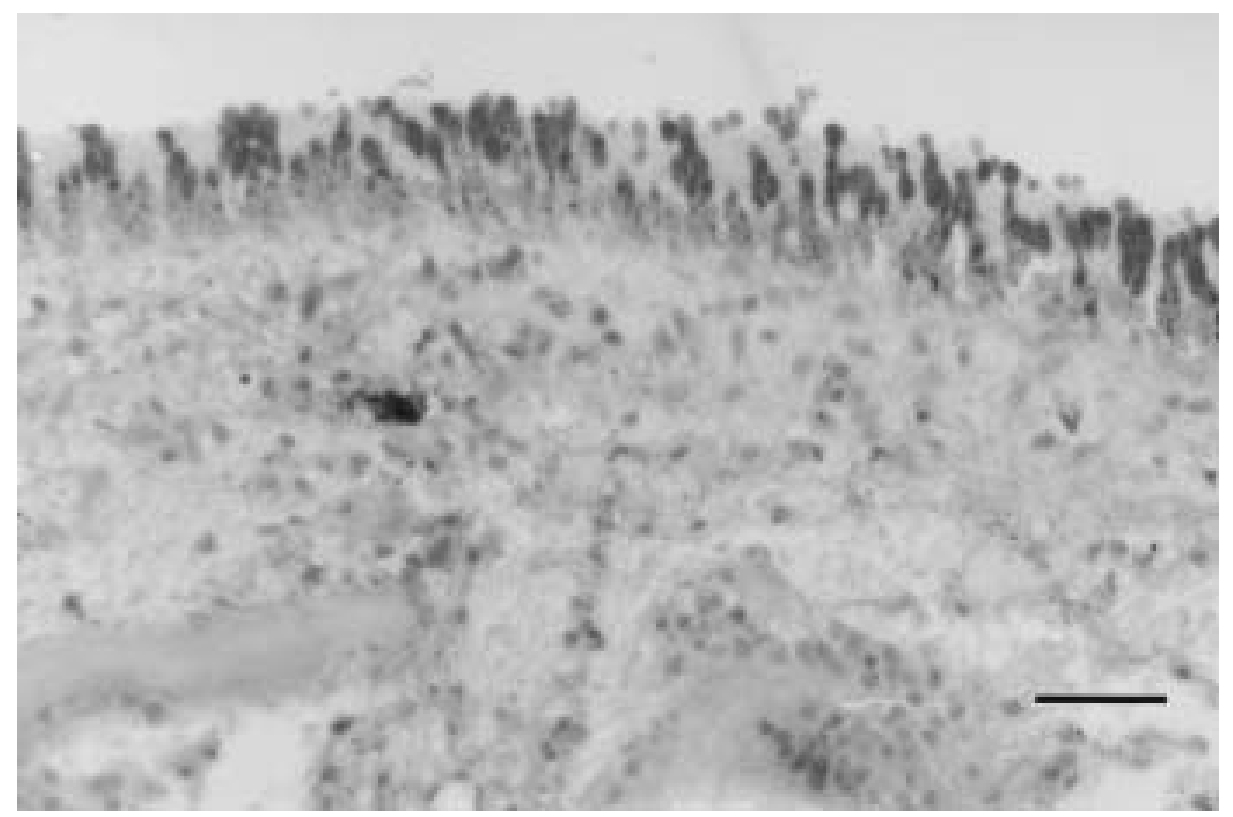

Fig. 6. Nasal mucosa from a conventionally raised $(\mathrm{CV})$ rat 3 weeks after experimental infection with Mycoplasma pulmonis. Oedema, infiltration of leucocytes and secretion in the lumen are seen. (Alcian blue-periodic acid Schiff stain; internal scale bar $=20 \mu \mathrm{M})$.
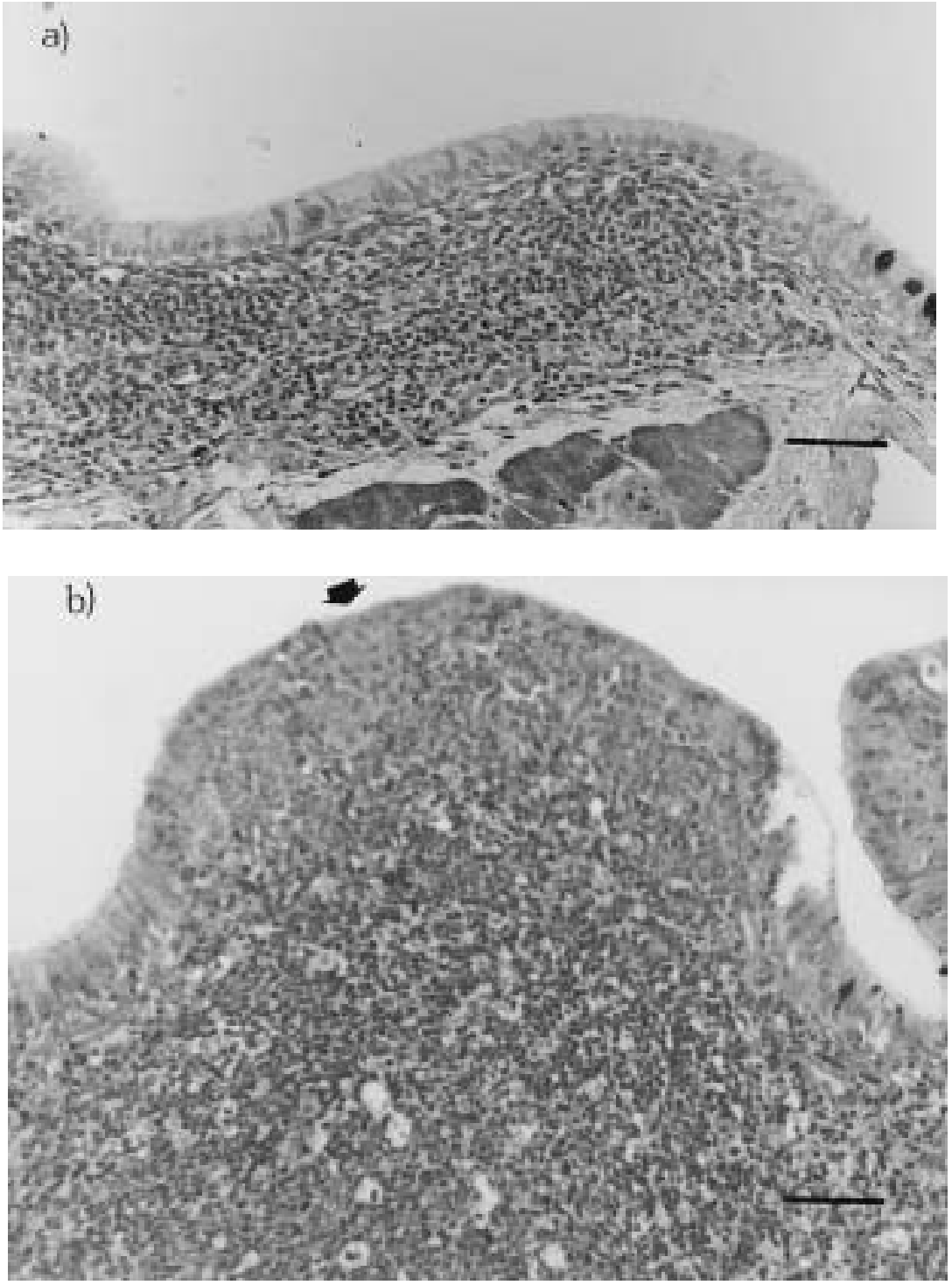

Fig. 7. - a) Comparatively flat subepithelial follicle-like aggregation of lymphocytes (germinal centre) in nasal mucosa of a germ free (GF) rat without experimental infection with Mycoplasma pulmonis, showing epithelium with a normal appearance and few infiltrating lymphocytes; b) voluminous germinal centre in nasal mucosa of a GF rat 3 weeks after experimental infection with $M$. pulmonis, showing numerous lymphocytes transcending an epithelium devoid of cilia (arrow). (Alcian blue-periodic acid Schiff stain; internal scale bars $=50 \mu \mathrm{M}$ ). 


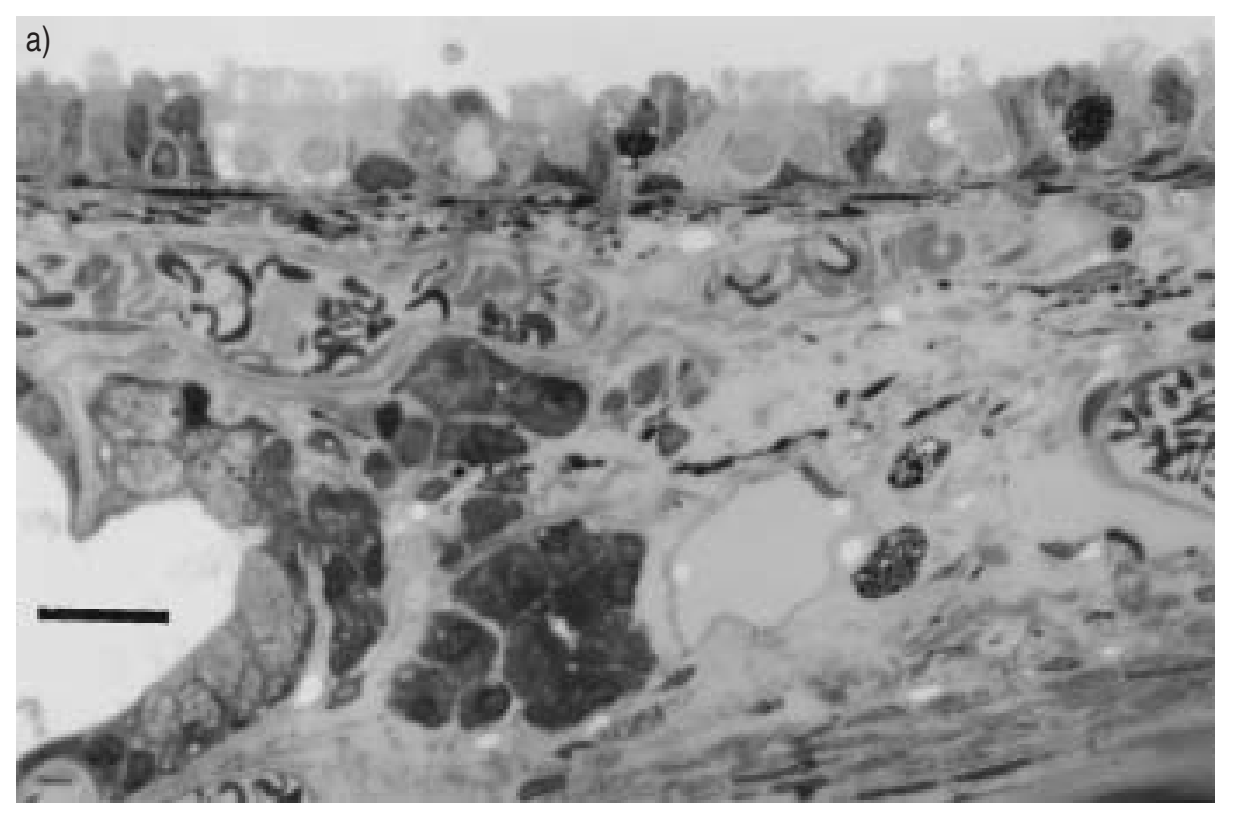

Fig. 8. - Tracheal mucosa from: a) a germ-free (GF) rat without experimental infection, showing thin and regularly arranged cuboidal epithelium, with no visible secretion in the lumen and no leucocytes in the lamina propria; b) a conventionally raised $(\mathrm{CV})$ rat sacrificed 3 weeks after experimental infection with Mycoplasma pulmonis. Notable findings are irregularity and partial loss of cilia and infiltration of polymorphonuclear cells. A gland acinus occluded by leucocytes can be seen (A) and there is proliferation of basal cells (arrow); c) the same rat as b), viewed by electromicroscopy, and demonstrating increased numbers of secretory cells with bipartite mucoid granules protruding from the apical portion of the cytoplasm. (a) and b) toluidine blue stain; internal scale bars $=50 \mu \mathrm{M} ; c)$ internal scale bar= $0.5 \mu \mathrm{M})$.

b)

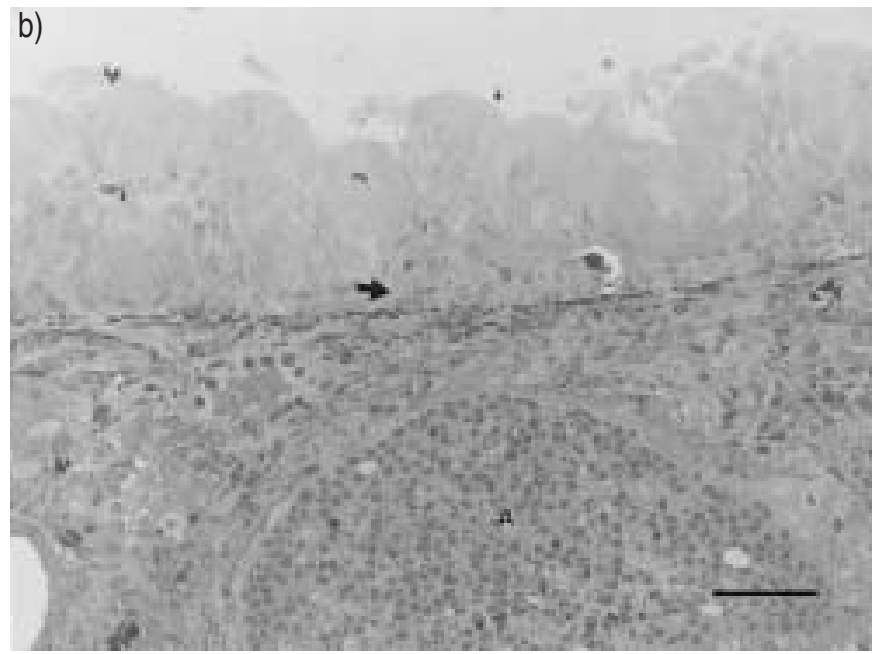

c)

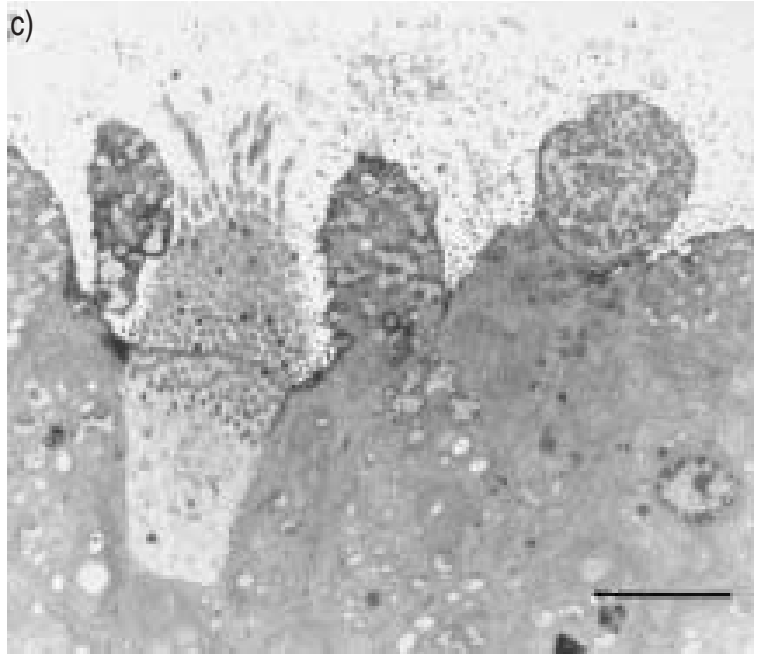

Trachea. The tracheal epithelium of infected animals, both CV and GF, was considerably thicker than that of uninfected rats, regardless of CV or GF. We found microabscesses and infiltration of mononuclear leucocytes in all infected rats (fig. 8).

\section{Bacteriological and clinical findings}

We re-isolated $M$. pulmonis from eight of the 10 infected SPF animals in experiment 1 and from all 10 infected animals in experiment 2 . At the time of sacrifice, most infected animals displayed localized loss of hair as a possible expression of generalized disease. One infected GF rat (experiment 2) had a purulent otitis media. However, there was no significant difference in weight between infected and uninfected animals.

\section{Discussion}

M. pulmonis infection of the upper airways in the rat appeared to increase SP-LI, and to some extent CGRP-
LI, in the nasal mucosa. This increase seems to be specific for the M. pulmonis infection and not related to interaction with the normal nasal flora since there was no difference between GF and CV rats after infection.

We still do not know whether the greater peripheral expression of SP and CGRP in the infected animals is accompanied by increased synthesis of the forerunners of these neuropeptides in the trigeminal ganglion. Although possible strain differences must be taken into account, our hypothesis was that the lack of bacterial influence on the mucosa in GF rats was the reason for the significantly lower ppCGRP expression in these rats, compared to that of infected SPF animals in experiment 1 . In experiment 2 we wished to test whether an M. pulmonis infection would increase the expression of ppCGRP and ppT more in GF rats than in rats of the same strain with an established normal flora, i.e. CV animals. The levels of ppCGRP and ppT expression were slightly higher in infected CV animals than in uninfected CV animals. However, these differences were not significant. It is possible that we would have had different results with a shorter or longer period of infection than in the present study ( 3 weeks). Another reason 
why we did not detect increased expression levels of ppCGRP and ppT in infected animals could be that we did not restrict our investigation to trigeminal ganglion cells with peripheral endings only in the nasal mucosa. The trigeminal nerve has three branches: the ophthalmic, the maxillary and the mandibular, all innervating different facial structures. SP- and CGRP-containing cells are small- to medium-sized with abundant localization, constituting $15-20 \%$ of all cells in nerve branches of the trigeminal ganglion. The afferents of the nasal receptors correspond to cell bodies in the ethmoidal portion of the ophthalmic branch of the trigeminal ganglion [15]. A focused examination, e.g. by in situ hybridization, might have revealed a more pronounced peptide expression in such cell bodies.

With the current design of oligodeoxynucleotide probes we intended to estimate total prohormonal biosynthesis. CGRP and SP can both be generated out of prohormonal products translated from several alternatively sliced mRNA transcripts. Four ppT transcripts $(\alpha, \beta, \gamma$ and $\delta$ ppT) encode for substance P $[13,16]$, while two ppCGRP transcripts ( $\alpha$ and $\beta p p C G R P$ ) encode for CGRP [12]. Thus, the current measurements did not allow us to detect changes attributable to a single transcript generated by alternative splicing. However, our measurements probably represent $\alpha$ pp-CGRP and $\gamma p p T$ mRNA expression, since these are the main transcripts in the rat trigeminal ganglion $[12,17]$.

Infections are often followed by a neurogenic response. A reduction in the regional content of enteric SP occurs in the inflamed intestines of parasitized ferrets [18]. In the airways, the inflammatory response to the release of sensory peptides may be potentiated by infection with influenza [19] or Sendai virus [20]. The agent we used, M. pulmonis, is an extracellular parasite that preferentially colonizes the luminal surface of respiratory epithelium. Infection with this organism can increase the vascular permeability induced by neurogenic inflammation in the rat trachea [21], although this effect is mediated by inhibition of the regulatory enzyme neutral endopeptidase (NEP) rather than by direct action on a neuropeptide [22]. Although M. pulmonis is known for its capacity to induce pneumonia, lung disease is difficult to reproduce consistently with this microorganism in the rat. In contrast, it is easy to establish an infection of the rat upper respiratory tract with M. pulmonis [23], which is supported by our present study, where this organism was reisolated from $90 \%$ of all infected animals after 3 weeks.

CGRP and SP are the main sensory neuropeptides in the trigeminal ganglion. They could, theoretically, contribute to the immune response in various ways. This hypothesis is supported by the findings of BowDEN et al. [24] who reported that destruction of sensory nerves in neonatal rats by systemic capsaicin treatment caused exacerbation of subsequent airway inflammation induced by experimental infection with $M$. pulmonis. CGRP is a potent vasodilator with a prolonged effect. Intravenously administered CGRP in cats causes pronounced vasodilation and increase in upper respiratory blood flow [25], and can, therefore, be considered an important contributor to inflammatory reaction. CGRP has also been suggested to have an anti-inflammatory effect on the airways since it inhibits the proliferative response of $\mathrm{T}$ - lymphocytes to mitogens, and counteracts macrophage secretion. However, CGRP has no direct effect on airway microvascular leak or nasal secretion [22]. CGRP immunoreactive nerve endings are frequent along arterioles, venules and gland acini in the mucosa of rat nasal septa and turbinates [26], which agrees with our findings. SP has been linked with many inflammatory effects in the airways, such as vasodilatation, plasma extravasation, goblet cell secretion, chemotaxis of inflammatory cells and production of immunoglobulin A $(\operatorname{Ig} \mathrm{A})$ and cytokines [3]. Important species variations have been noted. For example, nasal provocation with SP has a significant effect on secretion in rats and dogs, but not in humans [27]. SP-containing nerve fibres have been detected around nasal blood vessels beneath and within the surface epithelium [28], which is consistent with our findings. SP and CGRP overlap considerably in trigeminal cell bodies and in peripheral nerve fibres of the nasal mucosa, although some CGRP-immunoreactive cells do not contain SP [29]. Our findings also demonstrate a significant correlation between the rates of synthesis for each of these neuropeptides.

The nose is constantly exposed to noxious stimuli and, unlike the trachea and bronchi, is usually colonized with bacteria. The dense innervation and accumulation of vessels and glands make the tissue very reactive, and extensive epithelial changes may be found even in individuals without clinical signs of disease [30]. Hence, nasal mucosa unmodified by antigenic exposure can only be studied in animals raised under GF conditions. In our uninfected GF animals, subepithelial lymphoid aggregations were scarce and appeared inactive. Similar findings have been reported in studies of the gastrointestinal canals of GF rats [31] and in the nasal mucosa of GF mice [32]. While the intestinal flora is important for the wellbeing of the host, it is doubtful whether the normal nasal flora is similarly beneficial. Our GF animals did not appear to have a compromised immune defence system in their airways, even though they had been bred under GF conditions for more than 70 generations.

In conclusion, upper respiratory tract infections in humans are usually brief and self-limiting. In a prolonged infection such as chronic rhinitis or sinusitis, sensory neuropeptides may contribute to the regulation of the immune defence of the nasal mucosa. Experimental infection with Mycoplasma pulmonis in the rat is a suitable model for investigating infectious effects on sensory neuropeptides in the upper respiratory tract.

\section{References}

1. Barnes PJ. Asthma as an axon reflex. Lancet 1986; 1: 242-245.

2. Takeda N, Bukasa K, Yoshiyuki A, Morihiro I, Satoshi $\mathrm{O}$, Toru M. Neurogenic inflammation in nasal allergy: histochemical and pharmacological studies in guineapigs. A review. Acta Otolaryngol (Stockh) 1993; (Suppl. 501): 21-24.

3. Woodhead CJ. Neuropeptides in nasal mucosa. Clin Otolaryngol 1994; 19: 277-286.

4. Dusser D, Djokic T, Borson D, Nadel J. Cigarette smoke induces bronchconstrictor hyperresponsiveness to substance $\mathrm{P}$ and inactivates airway neutral endopeptidase 
in the guinea-pig: possible role of free radicals. J Clin Invest 1989; 84: 900-906.

5. Lundberg J, Lundblad L, Saria A, Änggård A. Inhibition of cigarette smoke-induced oedema in the nasal mucosa by capsaicin pretreatment and a substance $\mathrm{P}$ antagonist. Naunyn-Scmiedebergs Arch Pharmacol 1984; 326: 181185.

6. Kalubi B, Takeda N, Irifune M, et al. Nasal mucosa sensitization with toluene diisocyanate (TDI) increases preprotachykinin A (PPTA) and preproCGRP mRNAs in guinea-pig trigeminal ganglion neurons. Brain Research 1992; 576: 287-296.

7. Byers M, Taylor P. Reactions of dental sensory innervation to injury and inflammation. In: Inoki R, Kudo T, Olgart L, eds. Dynamic Aspects of Dental Pulp. London, Chapman and Hall, 1990; pp. 425-444.

8. Lacroix JS, Buvelot JM, Polla BS, Lundberg JM. Improvement of symptoms of non-allergic chronic rhinitis by local treatment with capsaicin. Clin Exp Allergy 1991; 21: 595-600.

9. McDonald D. Infections intensify neurogenic plasma extravasation in the airway mucosa. Am Rev Respir Dis 1992; (Suppl. 146): 40-44.

10. Norin K, Gustafsson B, Midtvedt T. Strain differences in faecal tryptic activity of germ-free and conventional rats. Laboratory Animals 1986; 20: 67-69.

11. Chomczynski P, Sacchi N. Single-step method of RNA isolation by acid guanidinium thiocyanate-phenolchloroform extraction. Anal Biochem 1987; 162: 156-159.

12. Amara S, Arriza J, Leff S, Swanson L, Evans R, Rosenfeld M. Expression in brain of a messenger RNA encoding a novel neuropeptide homologous to calcitonin generelated peptide. Science 1985; 229: 1094-1097.

13. Kawaguchi Y, Hoshimaru M, Nawa H, Nakanishi S. Sequence analysis of cloned cDNA for rat substance P precursor: existence of a third substance $\mathrm{P}$ precursor. Biochem Biophys Res Commun 1986; 139: 1040-1046.

14. Ponte P, Ng S-Y, Engel J, Gunning P, Kedes L. Evolutionary conservation in the untranslated regions of actin mRNAs: DNA sequence of a human $\beta$-actin cDNA. Nucl Acid Res 1984; 12: 1687-1696.

15. Lucier G, Egizii R. Evidence for the presence of substance $\mathrm{P}$ in the cat nasal receptor afferents. $J$ Chem Neuroanat 1988; 1: 303-310.

16. Harmar A, Hyde V, Chapman K. Identification and cDNA sequence of $\alpha$-preprotachykinin, a fourth splicing variant of the rat substance $\mathrm{P}$ precursor. FEBS Letters 1990; 275: $22-24$

17. Carter M, Krause J. Structure, expression and some regulatory mechanisms of the rat preprotachykinin gene encoding substance $\mathrm{P}$, neurokinin $\mathrm{A}$, neuropeptide $\mathrm{K}$, and neuropeptide G. J Neurosci 1990; 10: 2203-2214.

18. Palmer J, Greenwood B. Regional content of enteric substance $\mathrm{P}$ and vasoactive intestinal peptide during intestinal inflammation in the parasitized ferret. Neuropeptides 1993; 25: 95-103.
19. Jacoby D, Tamaoki J, Borson D, Nadel J. Influenza infection increases airway smooth muscle responsiveness to substance $\mathrm{P}$ in ferrets by decreasing enkephalinase. J Appl Physiol 1988; 64: 2653-2658.

20. Piedimonte G, Nadel J, Umeno E, McDonald D. Sendai virus infection potentiates neurogenic inflammation in rat trachea. J Appl Physiol 1990; 68: 754-760.

21. McDonald DM. Neurogenic inflammation in the respiratory tract: actions of sensory nerve mediators on blood vessels and epithelium of the airway mucosa. Am Rev Respir Dis 1987; (Suppl. 136): 65-72.

22. Barnes P, Baraniuk J, Belvisi M. Neuropeptides in the respiratory tract. Part II. Am Rev Respir Dis 1991; 144: 1391-1399.

23. Cassel G, Lindsey J, Baker H, Davis J. Mycoplasmal and rickettsial diseases. In: Baker $\mathrm{H}$, Lindsey J, Weisbroth S, eds. The Laboratory Rat. Vol 1. New York, Academic Press, 1979; pp. 243-269.

24. Bowden J, Baluk, P, Lefevre P, Schoeb T, Lindsey J, McDonald D. Sensory denervation by neonatal capsaicin treatment exacerbates Mycoplasma pulmonis infection in rat airways. Am J Physiol 1996; 270: L393-L403.

25. Hillerdal $\mathrm{M}$, Andersson S. The effects of calcitoningene related peptide on the blood flow of the upper respiratory tract and the middle and inner ear. Acta Otolaryngol (Stockh) 1989; 108: 94-100.

26. Chang-qing Z, Zheng-de T. An immunocytochemical study on the distribution of calcitonin gene-related peptidergic nerve fibers in rat nasal mucosa. Chinese Med $J$ 1994; 107: 781-784.

27. Petersson G, McCaffrey T, Malm L. Substance P and nasal secretion in dog, rat and man. Ann Allergy 1989; 62: 410-414.

28. Uddman R, Malm L, Sundler F. Substance P-containing nerve fibres in the nasal mucosa. Arch Otol Rhinol Laryngol 1983; 238: 9-16.

29. Stjärne P, Lundblad L, Änggård A, Hökfelt T, Lundberg J. Tachykinins and calcitonin-gene related peptide: coexistence in sensory nerves of the nasal mucosa and effects of blood flow. Cell Tissue Res 1989; 256: 439_ 446.

30. Jørgensen F, Hansson H. Morphological basis for impaired protective efficiency by the nasal mucosa in infants with and without recurrent acute otitis media: a light and electron microscopy study. Int Arch Allergy Appl Immunol 1990; 91: 257-265.

31. Okada Y, Setoyama H, Matsumoto S. Effects of fecal microorganisms and their chloroform-resistant variants derived from mice, rats, and humans on immunological and physiological characteristics of the intestines of ex-germ-free mice. Infect Immun 1994; 62: 5442-5446.

32. Ichimiya I, Kawauchi H, Tanaka T, Fujioshi T, Mogi G. Distribution of immunocompetent cells in normal nasal mucosa: comparisons among germ-free specific pathogen-free and conventional mice. Ann Otol Rhinol Laryngol 1991; 100: 638-642. 